\title{
Comparison of the Views of the General Dental Practitioners and Dental Interns in Asir, Saudi Arabia on Antibiotic Prescription for Endodontic Therapy: A Cross-Sectional Study
}

\author{
Mohammed A Alobaid (D) \\ Saad Alobaid ${ }^{2}$ \\ Mohammed Alshahrani ${ }^{3}$ \\ 'Restorative Dental Science Department \\ \& Department of Dental Education, \\ College of Dentistry, King Khalid \\ University, Abha, Saudi Arabia; ${ }^{2}$ Dental \\ Department, Medical Services/King \\ Khalid University Medical Hospital, Abha, \\ Saudi Arabia; ${ }^{3}$ Dental Clinic in Primary \\ Health Care Center, Ministry of Health, \\ Abha, Saudi Arabia
}

Aim: To assess the views of the dental interns (DIs) and general dental practitioners (GDPs) in the Asir region of Saudi Arabia on antibiotic prescription for endodontic therapy.

Methods: The link to a cross-sectional online survey with 16 quantitative and qualitative questions was e-mailed to 60 DIs at the College of Dentistry of King Khalid University (group 1 [G1]) and 60 GDPs at the governmental primary healthcare centers in the Asir region of Saudi Arabia (group 2 [G2]). The data obtained from the survey were then subjected to a comparative statistical analysis. The inter-group statistical comparison of the distribution of categorical variables was tested using the chi square test or the Fisher's exact probability test if more than $20 \%$ of the cells had an expected frequency of less than 5 . The p-values $>0.05$ were considered statistically significant. The data were statistically analyzed using Statistical Package for Social Sciences (SPSS version 22.0, IBM Corporation, USA) for MS Windows. Results: The response rate was $83.3 \%$ for G1 and $63.33 \%$ for G2. Of the participants in G2, $39.5 \%$ had 1-5 years' clinical experience (the participants in G1 had no clinical experience). The number of endodontic emergency patients seen per day was significantly higher in G1 ( $88 \%$ and $63.2 \%$ of the participants in G1 and G2, respectively, were seeing $0-3$ endodontic emergency patients per day). There was an insignificant difference between G1 and G2 in awareness of the existence of antibiotic prescription guidelines in endodontic therapy $(57.9 \%$ and $56.0 \%$, respectively; $\mathrm{p}>0.05$ ). There was also an insignificant difference between the groups in the rate of antibiotic prescription for endodontic problems, with $84 \%$ of the G1 participants and $86.8 \%$ of the G2 participants prescribing antibiotics only for limited patients. In the analysis of the clinical-vignette items (Q11-16), it was found that the rate of antibiotic prescription did not significantly differ between G1 and G2 (p > 0.05). No significant difference was found in the rate of antibiotic prescription for symptomatic reversible pulpitis, symptomatic irreversible pulpitis, and chronic apical periodontitis cases $(p>0.05)$. In contrast, the rate of antibiotic prescription for the symptomatic apical periodontitis, acute apical abscess, and systemic complications cases differed significantly ( $8 \%$ for G1 and $18.4 \%$ for $\mathrm{G} 2,54 \%$ for G1 and $76.3 \%$ for G2, and $98 \%$ for G1 and $73.7 \%$ for G2, respectively).

Conclusion: No significant difference in the rate of antibiotic prescription was found between the DIs and GDPs in this study. However, both groups showed an inappropriate rate of antibiotic prescription for some endodontic conditions. Further and more extensive studies involving a wider geographical region and different colleges of dentistry in Saudi Arabia are recommended.

Keywords: antibiotic in endodontics, antibiotic prescription, antibiotic over-use, antibiotics
Correspondence: Mohammed A Alobaid Tel +96656I343636

Email moalobaid@outlook.com;

manaseer@kku.edu.sa 


\section{Introduction}

As most human orofacial infections originate from odontogenic infections, antibiotic prescription is essential in dental practice. ${ }^{1}$ However, the misuse of antibiotics in different medical fields, including dentistry, has led to antibiotic-resistant bacterial species. ${ }^{2}$ Antimicrobial resistance is a serious clinical problem and poses risks to patients and future populations. ${ }^{3}$ It is predicted that multidrug-resistant infections will result in thousands of deaths annually, with substantial economic impacts. ${ }^{4}$ Although the rate of antibiotic prescription by dentists is not comparable to that by physicians, the role of dentists in the injudicious prescription of certain antibiotics is considerable. $^{5}$

In dentistry, antibiotics can be used prophylactically during invasive endodontic surgical procedures for patients found to have specific health conditions in a risk assessment. ${ }^{6,7}$ Antibiotics are also used in specific situations, such as for dental infections with systemic involvement ${ }^{7-10}$ and acute apical abscesses in medically compromised patients. ${ }^{7,10}$ However, many endodontic conditions can be managed with local measures, without antibiotics. $^{8,9,11}$ The appropriate use of antibiotics for endodontic therapy requires an understanding of the endodontic-disease treatment processes and the bacterial species responsible for the infection. Antibiotics should be used only when required for specific cases; when there is no bacterial invasion of the root canal system during reversible or irreversible pulpitis, for instance, antibiotics are not required. ${ }^{12}$

In Saudi Arabia, several studies have been carried out to assess dentists' awareness of the existence of antibiotic prescription guidelines and indications for endodontic therapy. In one study, $65.9 \%$ of the participants did not follow any specific guideline and frequently prescribed antibiotics in situations where this was neither necessary nor indicated. ${ }^{13}$ These previous studies targeted general dentists and focused on specific cities around the country. However, it would also be useful to compare dental interns' (DIs) knowledge of the antibiotic prescription guidelines and indications to that of general dental practitioners (GDPs) to determine if the dental undergraduate curriculum needs to be updated to account for the new antibiotic prescription guidelines. The potential for indiscriminate antibiotic prescription by dentists is probably higher in certain countries, such as Saudi Arabia, in which there are few restrictions to dentists' antibiotic prescription. The current recommendations for antibiotic prescription in endodontics are guided by specialist endodontic associations such as the American Association of Endodontists and the European Society of Endodontology (ESE) and dental bodies such as the Scottish Dental Clinical Effectiveness Programme. There is a consensus that the local treatment measures (ie, caries excavation or restoration, pulpotomy, pulpectomy, surgical incision, drainage of soft-tissue swellings, and extraction) are sufficient to contain endodontic infections. ${ }^{7-11}$

DIs are in their final stages of training and will soon be qualified to start their clinical practice as GDPs, which means that they will be able to prescribe antibiotics independently, without requiring their supervisors' input. Besides, DIs can already provide evidence of what they have learned and assimilated during their education, which they will apply to their professional practice. On the other hand, GDPs are professionals subjected to various environmental factors, such as time pressure while seeing their patients, which has been described as a factor contributing to inappropriate antibiotic prescriptions. ${ }^{14}$ Therefore, this study aimed to evaluate the views of the DIs and GDPs in the Asir region of Saudi Arabia on antibiotic prescription for endodontic conditions. The null hypothesis for this study was that there is no statistical difference between the views of the DIs and GDPs in the Asir region of Saudi Arabia on antibiotic prescription for endodontic conditions.

\section{Materials and Methods}

The conduct of this study was approved by the Institutional Review Board of King Khalid University, College of Dentistry KKUCOD (Approval No. IRB/ KKUCOD/ETH/2020-21/017). An online survey was conducted, with the questionnaire consisting of generalknowledge questions about antibiotics and clinical vignettes where the participants were asked to indicate whether there is a need for antibiotic prescription or there is none.

The questionnaire was developed following the Checklist for Reporting Results of Internet E-Surveys (CHERRIES) $^{15}$ (see Appendix 1). A total of 120 online survey participation invitations were sent to two groups: group 1 (G1) consisting of the DIs at the College of Dentistry of King Khalid University $(n=60)$ and group 2 (G2) consisting of GDPs in the governmental sector within the region of Asir, Saudi Arabia $(n=60)$. The invitations were sent individually via the Dental Internship Committee at KKUCOD for G1 and the General Directorate of Health 
Affairs of the Asir region for G2. The online survey was made accessible from October 30, 2020, to November 30, 2020 , and reminders were sent weekly to the invitees after the survey was launched.

The questionnaire consisted of 16 qualitative and quantitative questions (Appendix 2). The first 10 questions asked about general information regarding the participants, such as the college of dentistry where they graduated, occupation, years of experience, number of emergency patients seen per day, frequency of antibiotic prescription for each working day, and awareness of the existence of antibiotic prescription guidelines for endodontic therapy. The remaining six questions included clinical vignettes, where the participants were asked to state whether they would or would not prescribe antibiotics in each of the cases. The correct answers were based on the available antibiotic prescription guidelines, ${ }^{8-10}$ (Appendix 2).

\section{Survey Design}

The online survey questionnaire was constructed by the research team (consisting of an academician/endodontist consultant and two general dentists with 10 years' experience), relying on previous studies related to the topic. ${ }^{16,17}$ It was piloted with two DI and two GDP participants for validation purposes. The questionnaire consisted of three main pages, as described below.

Page 1

- "Participants' information sheet (PIS)" was the first page of the online survey questionnaire. It included all the information that the participants needed to know as regards the study, such as the study title and objectives and the researchers' contact details.

- The "Consent Form" followed, which included three compulsory questions with "Yes" or "No" response options, as shown below.

○ I understand that my participation is voluntary and that I am free to withdraw at any time, without giving any reason for such.

o I agree to take part in this study.

○ I understand that the researchers intend to publish the results of this study in a scientific manuscript and/or poster, where all the published data will be anonymous, and the study participants will not be identified.

Page 2: Titled "Questionnaire," it contained generalinformation questions.
Page 3: Titled "Questionnaire," it contained the clinical-vignette items.

\section{Data Analysis}

All the data were collected anonymously and were shown as categorical variables ( $\mathrm{n} ; \%$ of the participants). The inter-group statistical comparisons of the categorical variables' distributions were tested using the chi square test or the Fisher's exact probability test if more than $20 \%$ of the cells had an expected frequency of less than 5. P-values $<$ 0.05 were considered statistically significant. All the data were statistically analyzed using Statistical Package for Social Sciences (SPSS version 22.0, IBM Corporation, USA) for MS Windows.

\section{Results}

A total of 88 responses were received (from 50 of the 60 DIs in G1 [83.3\%] and from 38 of the 60 GDPs in G2 [63.33\%]). Table 1 shows a summary of the responses to questions 1-9 (Q1-9). In regard to the distribution of the number of endodontic emergency patients seen per day, it differed significantly between G1 and G2 ( $p<0.05$ ), with a significantly higher number of endodontic emergency patients seen per day by the G2 participants.

For Q5, the distribution of the rate of antibiotic prescription for endodontic problems did not differ significantly between $\mathrm{G} 1$ and $\mathrm{G} 2(\mathrm{p}>0.05)$. For Q6, the distribution of opinions regarding the conditions for which antibiotics should not be prescribed (eg, symptomatic reversible pulpitis, symptomatic irreversible pulpitis, chronic apical periodontitis) did not differ significantly between G1 and G2 ( $p>0.05$ for all). However, the distribution of opinions regarding the conditions for which antibiotics should be prescribed (eg, symptomatic apical periodontitis, acute apical abscess, and systemic complications) significantly differed between the two groups ( $p<0.05$ for all). A significantly higher proportion of G1 participants than G2 participants cited "systemic complications" (the correct answer) as a condition for which antibiotics should be prescribed $(\mathrm{p}<0.05)$.

For Q7, the distribution of the awareness of the existence of antibiotic prescription guidelines for endodontic conditions did not differ significantly between G1 and G2 (57.9\% vs 56.0\%; p >0.05). The difference was statistically insignificant as well for Q8 and Q9 ( $\mathrm{p}>0.05)$.

In the analysis of the participants' answers to the clinical vignettes (Q11-16, Figures 1 and 2), it was found that the 
Table I General Summary of the Answers of the Dental Interns and General Dental Practitioners in This Study to Questions I-9

\begin{tabular}{|c|c|c|c|c|}
\hline & Questions & $\begin{array}{c}\text { GI (Dental } \\
\text { Interns) } \mathbf{N}=\mathbf{5 0}\end{array}$ & $\begin{array}{l}\text { G2 (General Dental } \\
\text { Practitioners) } \mathbf{N}=38\end{array}$ & P-value \\
\hline Q I & $\begin{array}{l}\text { Qualified dental school participants from } \\
\text { College of Dentistry, King Khalid University }\end{array}$ & $50(100 \%)$ & $38(100 \%)$ & \\
\hline Q2 & Occupation & $50(57 \%)$ & $38(43 \%)$ & \\
\hline Q3 & $\begin{array}{l}\text { Years of clinical experience } \\
\text { Less than I year } \\
\text { I-5 years } \\
5-10 \text { years } \\
\text { More than } 10 \text { years }\end{array}$ & $\begin{array}{l}0 \\
0 \\
0 \\
0\end{array}$ & $\begin{array}{l}10(26 \%) \\
12(31.6 \%) \\
15(39.5 \%) \\
1(2.6 \%)\end{array}$ & $<0.001$ \\
\hline Q4 & $\begin{array}{l}\text { Number of endodontic emergency patients per day } \\
0-3 \\
3-6 \\
6-9 \\
9-12\end{array}$ & $\begin{array}{c}44(88 \%) \\
4(8 \%) \\
\text { I }(2 \%) \\
\text { I }(2 \%)\end{array}$ & $\begin{array}{l}24(63.2 \%) \\
13(34.2 \%) \\
\text { I }(2.6 \%) \\
0\end{array}$ & $<0.05$ \\
\hline Q5 & $\begin{array}{l}\text { How frequently they prescribe antibiotics for endodontic } \\
\text { problems } \\
\text { To a limited number of patients } \\
\text { To most patients } \\
\text { To all patients } \\
\text { Never }\end{array}$ & $\begin{array}{c}42(84 \%) \\
6(12 \%) \\
0 \\
2(4 \%)\end{array}$ & $\begin{aligned} & 33(86.8 \%) \\
& 3(7.9 \%) \\
& \text { I }(2.6 \%) \\
& \text { I }(2.6 \%)\end{aligned}$ & $>0.05$ \\
\hline Q6 & $\begin{array}{l}\text { Which endodontic condition requires antibiotic use } \\
\text { Symptomatic reversible pulpitis } \\
\text { Symptomatic irreversible pulpitis } \\
\text { Symptomatic apical periodontitis } \\
\text { Chronic apical periodontitis } \\
\text { Acute apical abscess } \\
\text { Systemic complications }\end{array}$ & $\begin{array}{l}\text { I (2\%) } \\
4(8 \%) \\
2(4 \%) \\
5(10 \%) \\
27(54 \%) \\
49(98 \%)\end{array}$ & $\begin{array}{c}5(13.2 \%) \\
2(5.3 \%) \\
7(18.4 \%) \\
9(23.7 \%) \\
29(76.3 \%) \\
28(73.7 \%)\end{array}$ & $\begin{array}{l}>0.05 \\
>0.05 \\
<0.05 \\
>0.05 \\
<0.05 \\
<0.05\end{array}$ \\
\hline Q7 & $\begin{array}{l}\text { Aware of existence of antibiotic prescription guidelines for } \\
\text { endodontic conditions }\end{array}$ & $28(56 \%)$ & $22(57.9 \%)$ & $>0.05$ \\
\hline Q8 & $\begin{array}{l}\text { Have read available antibiotic prescription guidelines for } \\
\text { endodontic conditions }\end{array}$ & $22(44 \%)$ & $22(57.9 \%)$ & $>0.05$ \\
\hline Q9 & Aware of antibiotic overuse consequences & $40(80 \%)$ & 27 (7I.1\%) & $>0.05$ \\
\hline
\end{tabular}

distribution of responses regarding antibiotic use did not differ significantly between G1 and G2 ( $p>0.05)$.

\section{Discussion}

This study aimed to assess the views of the DIs at the College of Dentistry of King Khalid University and of the GDPs within the Asir region of Saudi Arabia on antibiotic indications for endodontic therapy via an online survey. Overall, the results indicate no statistically significant difference between the DIs and GDPs. This study result differs from those of the studies by Martin-Jimenez et al ${ }^{16}$ and Al Masan et $\mathrm{al}^{17}$ which investigated the same topic. The possible explanation of this difference is that this study's sample included DIs and GDPs while the two aforementioned studies involved undergraduate dental students. Most of the participants in both groups in this study were aware that there were available antibiotic prescription guidelines in endodontics, but less than half of them had read such guidelines. Both groups were aware of the consequences of the overuse of antibiotics, such as global antibiotic resistance, with no significant difference between the DIs and the GDPs $(71.1 \%$ vs $80.0 \%$; p > 


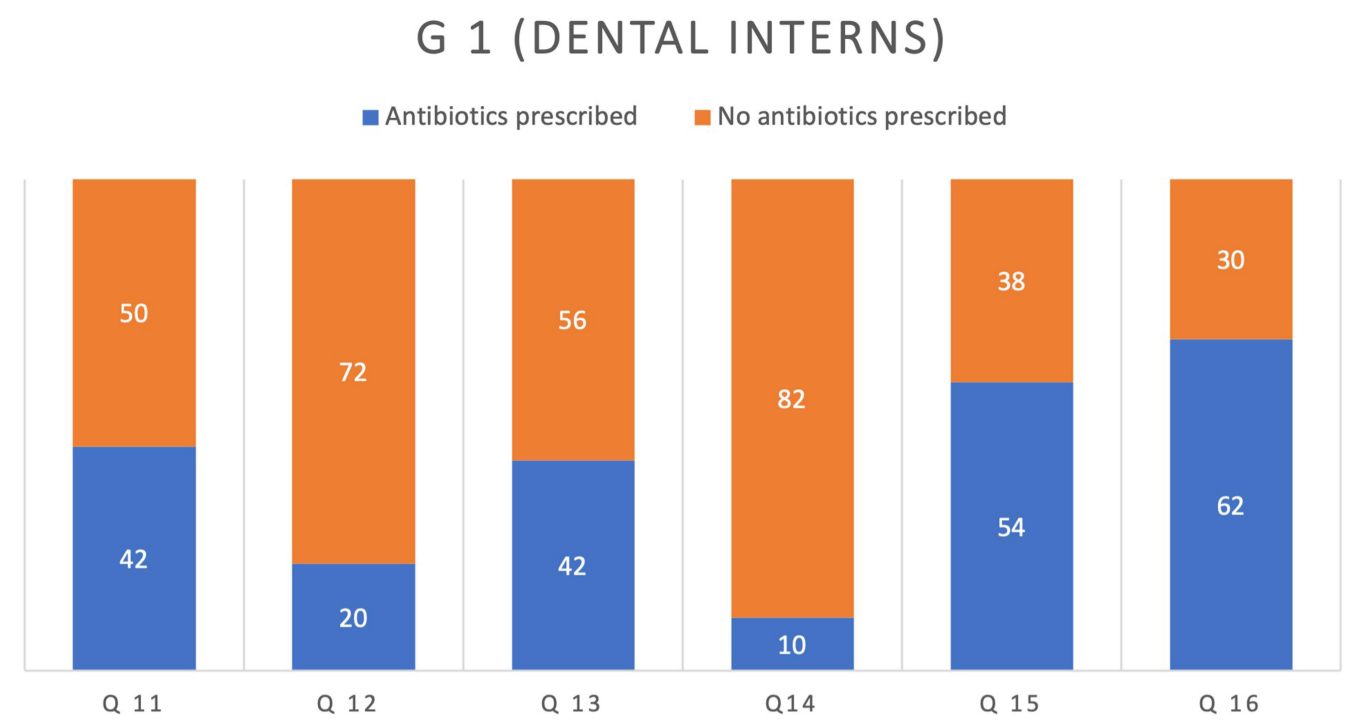

Figure I Responses of the GI (group I) participants (dental interns, $n=50$ ) to the questions on antibiotic indications for treating different endodontic clinical cases (QI I16 [questions II-16]). The percentages are indicated by the bars' size on the chart for the scale shown on the $y$-axis whereas the labels indicate the number of subjects. Correct answer for Q II-16: Antibiotic is not indicated in all the cases except for Q16 ( $>0.05$, which is considered statistically insignificant for QII-I6).

0.05). There was also no significant difference between the groups' attitudes toward antibiotic prescription by clinical experience, contrary to the study by $\mathrm{Al}$ Masan et $\mathrm{al}^{17}$ and similar to the study by Al-Huwayrini et al. ${ }^{18}$ The possible explanation of this is that both groups in this study were keeping themselves updated regarding the aforementioned guidelines.

Piloting a questionnaire gives an early indication of the revisions that need to be made in the questions, even though it does not ensure the definitive success of the study. ${ }^{19}$ A pilot study was thus conducted before the questionnaire was distributed to the participants. The survey questionnaire was piloted with two DIs and two GDPs to validate the questions. Although the number of participants in the pilot stage was low, this was nonconsequential because this stage just aimed to determine if there was a need to revise the questions. ${ }^{19}$ The aim of piloting was achieved as many comments regarding the outline of the questions and the font that was used were obtained therefrom. The required minimum response rate

\section{G 2 (General Dental Practitioners)}

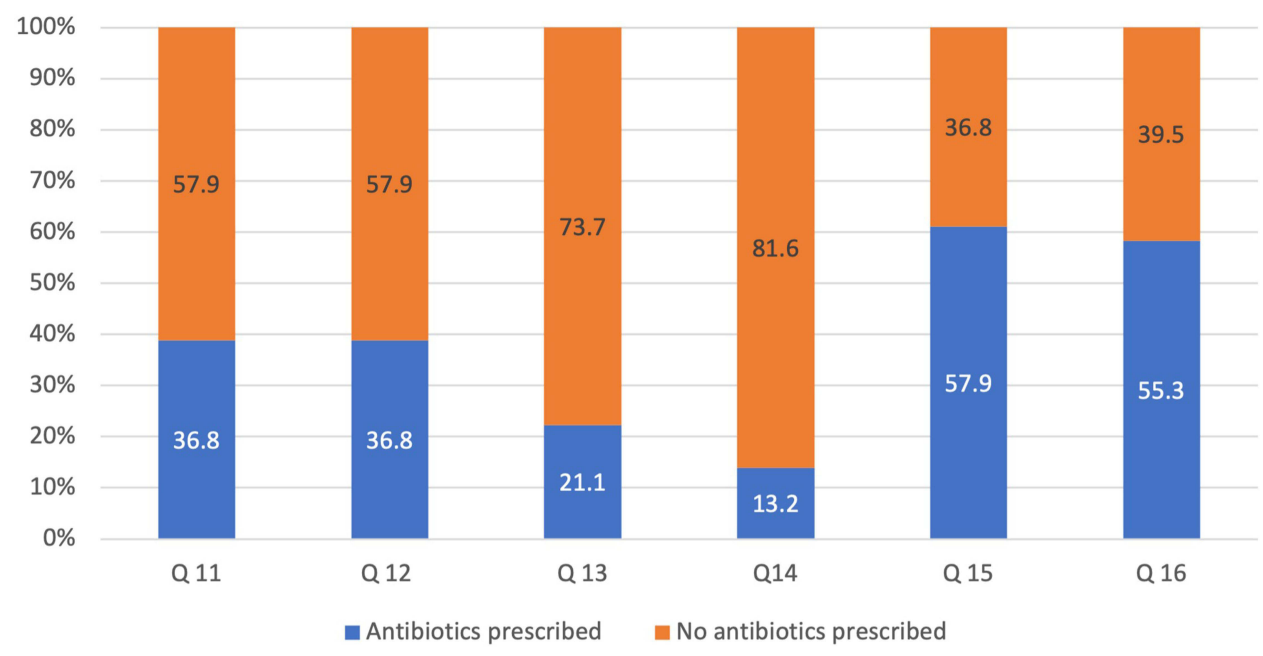

Figure 2 Responses of the G2 (group 2) participants (general dental practitioners, $n=38$ ) to the questions on antibiotic indications for treating different endodontic clinical cases (Q II-16 [questions II-16]). The percentages are indicated by the bars' size on the chart for the scale shown on the $y$-axis whereas the labels indicate the number of subjects. Correct answer for QII-16: Antibiotic is not indicated in all the cases except for QI6 ( $>0.05$, which is considered statistically insignificant for QII-16). 
is not clearly reflected in the literature, but a $70-80 \%$ response rate is considered adequate by some authors to exclude non-response bias. ${ }^{20,21}$ This study's response rate was comparable to those of the previous studies in the literature. ${ }^{10,17,22-24}$ Response rates may vary due to factors such as the questionnaire topic, the difference between the respondents and the non-respondents, the sample selection and size, the targeted group type, the questionnaire design, and the distribution method used. ${ }^{25}$ In this study, the response rates remained extremely low until the DIs were approached during their clinical sessions; the researchers e-mailed the groups' representatives, asking them to encourage their fellow DIs to participate in the study. Although this method was time consuming, its effect was noticeable as the response rate increased from $20 \%$ at the opening of the survey to $83.3 \%$ at the time that the survey closed, which is similar to the response rates obtained by $\mathrm{Al}$ Masan et al. ${ }^{17}$ Barclay et $\mathrm{al}^{26}$ and Nulty et al. ${ }^{27}$ The effect of reminders on increasing the response rate, however, is controversial in the literature; some endorse its effectiveness ${ }^{26,27}$ while others do not. ${ }^{28}$ In this study, a small percentage of the participants in both groups stated that they would never prescribe antibiotics for endodontic conditions (Q6). This could be because such participants misunderstood the question or lacked knowledge about the matter. Even though the local dental treatment measure is sufficient to manage an acute apical abscess and there is no need to prescribe antibiotics, ${ }^{7-10}$ a high percentage of the participants in both groups (G1 = $54 \%, \mathrm{G} 2=76.3 \%$ ) stated that acute apical abscess was an indication for antibiotic prescription (Q7). This trend of overusing antibiotics for treating this condition was in agreement with the results obtained by Martin-Jimenez et $\mathrm{al}^{16}$ and $\mathrm{Al}$ Masan et al. ${ }^{17}$

The clinical-vignette items (Q11-16) were designed to reflect controversial clinical conditions with a variety of clinical presentations. The questions and answers were designed to include both quantitative data (as options: antibiotics indicated or no antibiotics indicated) and qualitative data (a space was provided for the participants to justify their answers). The correct answers for Q11-15 was that antibiotic prescription is not indicated, but that for Q16 was that antibiotic prescription is indicated. The majority of the participants in both groups $(\mathrm{G} 1=50 \%$, $\mathrm{G} 2=57.9 \%$ ) would not prescribe antibiotics to treat teeth with necrotic pulp tissue and symptomatic apical periodontitis (Q11), which is in contrast to the results obtained by Martin-Jimenez et al ${ }^{16}$ and Al Masan et al. ${ }^{17}$ However, non-negligible percentages of the participants in both groups in this study ( $\mathrm{G} 1=42 \%, \mathrm{G} 2=36.8 \%$ ) would prescribe antibiotics for such cases. The possible explanation of these high percentages (albeit not the majority) is that the participants might have understood that a patient's "feeling feverish" was an indication of systemic involvement. Indeed, several participants justified their answers by stating that the patient had fever, which is considered a sign of systemic involvement. The word feverish was added to assess the participants' ability to assess systemic complications as the term systemic complications can be vague. ${ }^{9}$ Hence, clinicians should use an objective method of assessing such complications to avoid overusing antibiotics for such cases. ${ }^{29}$

In a clinical vignette of failed root canal treatment (Q12), the use of antibiotics associated with localized symptoms without systemic complications is not indicated. ${ }^{10}$ The majority of the participants in both groups would not prescribe antibiotics for such cases (G1 $=72 \%$, $\mathrm{G}=57.9 \%$ ). Several participants justified their answer that there is a need for antibiotic prescription in such case by stating that pain is present and it needs to be relieved before starting secondary root canal treatment, and that antibiotics must be prescribed to be able to give adequate local anesthesia. Pain was highlighted in a previous study as a factor influencing GDPs' antibiotic prescription. ${ }^{14}$ However, there is accumulating evidence that there are alternative effective measures to control pain, such as providing analgesics and local treatment without the need for antibiotic prescription. ${ }^{30-34}$ Q13 aimed to assess the participants' updated knowledge of the new guidelines on antibiotic prophylactic use for patients with a history of rheumatic fever and with a diagnosis of necrotic pulp with asymptomatic apical periodontitis. In this clinical vignette, the patient's history indicated the occurrence of rheumatic fever 28 years ago. According to the National Institute for Health and Care Excellence guidelines and latest review updates ${ }^{6}$ and the latest $\mathrm{ESE}^{7}$ position statement for antibiotics used in endodontics, antibiotic prophylaxis is not indicated for such condition during dental treatment. Approximately half of the G1 participants and $73.3 \%$ of the G2 participants would not prescribe antibiotics for such cases. The participants who would prescribe antibiotics despite the latest guidelines justified their answer that antibiotics should be prescribed in such case by stating that antibiotic prescription in such case is a prophylactic measure because the history of rheumatic fever is considered a high-risk condition. ${ }^{6,7}$ 
Failure to achieve profound local anesthesia is not an indication for antibiotic prescription (Q14), but $10 \%$ of the G1 participants and $13 \%$ of the G2 participants would prescribe antibiotics in cases where local anesthesia was not effective, without giving any reason for their answer. Among the perceived causes of failed local anesthesia are the presence of accessory nerves, ion trapping, anxiety, and central core theory. ${ }^{35}$ The correct approach in such cases is to use alternative techniques for achieving local anesthesia. ${ }^{36}$ Q15 described a patient who had poorly controlled diabetes, with signs and symptoms of chronic apical periodontitis. Fifty-four percent of the G1 participants and $57.9 \%$ of the $\mathrm{G} 2$ participants favored antibiotic use in such case, which is not the correct answer. Antibiotics are not required for chronic apical abscess without systemic involvement. A patent sinus tract provides continuous drainage; besides, no systemic involvement was presented in the clinical vignette. Ideally, local measures such as initiation of primary root canal treatment must be resorted to, with possible patient advice to use post-operative analgesic for pain control. The fact that the patient is diabetic and that his diabetes status is poorly controlled does not indicate antibiotic prescription to control the endodontic condition. Rather, it indicates the need for liaising with the patient's medical physician to control his diabetic status. ${ }^{37}$ Q16 was the only clinical vignette where the use of antibiotics was indicated because of the signs of spreading infection, risk of cellulitis, and associated risk of infection in dangerous areas, which can affect the vital body functions, such as breathing. ${ }^{7-9}$ Sixty-two percent of the G1 participants and $55.3 \%$ of the G2 participants would prescribe antibiotics in such case, but $30 \%$ of the G1 participants and $34.5 \%$ of the G2 participants would not and justified their answer by stating that root canal treatment and daily monitoring of this situation are enough to manage such case.

The online administration of survey questionnaires has many apparent advantages and is increasing in popularity. Online surveys are economical, easy to access, rapid, and efficient methods of collecting data. ${ }^{38-40}$ One of the critical ethical advantages of using an online survey software tool is that the respondents cannot be traced. There is also no need to use e-mail addresses, and there is a lower likelihood of invading the respondents' privacy. However, as it is not possible to verify the respondents' identity in any way, the people who should be excluded from the survey (in the current study, undergraduate dental students) may end up being included in the survey. The researcher has only minimal control over the respondents' access to and engagement with the material. This may be considered one of the limitations of this study as the data could have been contaminated if the excluded population had access to and completed the questionnaire. In addition, the questionnaire method of collecting data for research purposes obtains only a "snapshot" of the participants' knowledge level at the time that they took the survey. The same cohort of participants was not followed up over time, and as such, their career progress was not accounted for. Another limitation of this study was its small targeted sample size. As the current study was limited to one region in Saudi Arabia, there was a limited number of participants in both groups that could be included. This might have affected the external validity of this study and its ability to represent these two groups all over the country. However, it must be noted that although the targeted sample size was small, the response rate of this study was comparable to those of the previous relevant studies in the literature. ${ }^{17,22-25}$

This study's results could be attributed to the current bachelor dental programs in Saudi Arabia. Dental students are often exposed to oral-infection conditions, and their clinical use of antibiotics for such cases with insufficient knowledge of the guidelines regarding their use will affect their management of the patient's dental condition. Furthermore, offering continuing dental education courses providing proper and up-to-date knowledge on this topic may help improve the use of antibiotics for endodontic conditions.

\section{Conclusion}

This study revealed that both the DI and GDP participants could prescribe antibiotics for endodontic conditions where they are not indicated. Further studies including a larger sample, a wider geographical region, and different colleges of dentistry within Saudi Arabia can provide better ideas of the reasons behind the misuse of antibiotics for endodontic conditions.

\section{Ethics and Consent}

In this study, all participants were provided informed consent in accordance with the Declaration of Helsinki.

\section{Disclosure}

The authors report no conflicts of interest for this work. 


\section{References}

1. Dar-Odeh NS, Abu-Hammad OA, Al-Omiri MK, Khraisat AS, Shehabi AA. Antibiotic prescribing practices by dentists: a review. $J$ Ther Clin Risk Manage. 2010;6:301-306. doi:10.2147/TCRM. S9736

2. Ventola CL. The antibiotic resistance crisis: part 1: causes and threats. Pharmacol Ther. 2015;40:277.

3. Davies SC, Fowler T, Watson J, Livermore DM, Walker D. Annual report of the chief medical officer: infection and the rise of antimicrobial resistance. Lancet. 2013;381:1606-1609.

4. O'Neill J. Tackling Drug-Resistant Infections Globally: Final Report and Recommendations. London: Wellcome Trust \& HM Government; 2016.

5. Halboub E, Alzaili A, Quadri MFA, Al-Haroni M, Al-Obaida MI, Alhebshi NN. Antibiotic prescription knowledge of dentists in Kingdom of Saudi Arabia: an online, country-wide survey. J Contemp Dent Pract. 2016;17(3):198-204. doi:10.5005/jp-journals-10024-1827

6. National Institute for Health and Care Excellence. Prophylaxis against infective endocarditis: antimicrobial prophylaxis against infective endocarditis in adults and children undergoing interventional procedures; 2016. Available from https://www.nice.org.uk/gui dance/cg64. Accessed July 21, 2021.

7. Segura-Egea JJ, Gould K, Hakan Şen B; European Society of Endodontology. European Society of Endodontology position statement: the use of antibiotics in endodontics. Int Endod J. 2018;51:20-25. doi:10.1111/iej.12781

8. Scottish Dental Clinical Effectiveness Programme. Drug prescribing for dentistry, dental clinical guidance; 2011. Available from: https:// www.sdcep.org.uk/published-guidance/drug-prescribing/. Accessed July 28, 2021.

9. American Association of Endodontists. Antibiotics: a risky prescription; 2016. Available from https://www.aae.org/specialty/communi que/antibiotics-a-risky-prescription/. Accessed July 21, 2021.

10. Segura-Egea JJ, Gould K, Hakan-Sen B, et al. Antibiotics in endodontics: a review. Int Endod J. 2017;50:1169-1184. doi:10.1111/ iej. 12741

11. Sharif F. Antimicrobial Prescribing for General Dental Practitioners. London, UK: Faculty of General Dental Practice (UK); 2015.

12. Haapasalo M, Endal U, Zandi H, Coil JM. Eradication of endodontic infection by instrumentation and irrigation solutions. Endod Topics. 2005;10:77-102. doi:10.1111/j.1601-1546.2005.00135.x

13. Al-Johani K, Reddy SG, Al Mushayt AS, El-Housseiny A. Pattern of prescription of antibiotics among dental practitioners in Jeddah, KSA: a cross-sectional survey. Niger J Clin Pract. 2017;20:804-810.

14. Cope AL, Francis NA, Wood F, Chestnutt IG. Antibiotic prescribing in UK general dental practice: a cross-sectional study. Community Dent Oral Epidemiol. 2015;44:145-153. doi:10.1111/cdoe.12199

15. Eysenbach G. Improving the quality of web surveys: the Checklist for Reporting Results of Internet E-Surveys (CHERRIES) [published correction appears. J Med Internet Res. 2004;6(3):e34. doi:10.2196/ jmir.6.3.e34

16. Martin-Jimenez M, Martin-Biedma B, Lopez-Lopez J, et al. Dental students' knowledge regarding the indications for antibiotics in the management of endodontic infections. Int Endod J. 2018;51:118-127. doi:10.1111/iej.12778

17. Al Masan AA, Dummer PMH, Farnell DJJ, Vianna ME. Antibiotic prescribing for endodontic therapies: a comparative survey between general dental practitioners and final year Bachelor of Dental Surgery students in Cardiff, UK. Int Endod J. 2018;51:717-728. doi:10.1111/ iej. 12887

18. Al-Huwayrini L, Al-Furiji S, Al-Dhurgham R, Al-Shawaf M, AlMuhaiza M. Knowledge of antibiotics among dentists in Riyadh private clinics. Saudi Dent J. 2013;25(3):119-124. doi:10.1016/j. sdentj.2013.05.001
19. Van Teijlingen E, Hundley V. The importance of pilot studies. Nurs Stand. 2002;16:33-36. doi:10.7748/ns2002.06.16.40.33.c3214

20. Evans SJ. Good surveys guide. Br Med J. 1991;302:302-303. doi:10.1136/bmj.302.6772.302

21. Christie D, Gordon I, Heller RF. Epidemiology: An Introductory Text for Medical and Other Health Science Students. Sydney, Australia: UNSW Press; 1997.

22. Palmer NAO, Pealing R, Ireland RS, Martin MV. Therapeutics: a study of prophylactic antibiotic prescribing in National Health Service general dental practice in England. $\mathrm{Br}$ Dent $J$. 2000;189:43-46. doi:10.1038/sj.bdj.4800597

23. Rodriguez-Nunez A, Cisneros-Cabello R, Velasco-Ortega E, LlamasCarreras JM, Torres-Lagares D, Segura-Egea JJ. Antibiotic use by members of the Spanish Endodontic Society. $J$ Endod. 2009;35:1198-1203. doi:10.1016/j.joen.2009.05.031

24. Cunningham CT, Quan H, Hemmelgarn B, et al. Exploring physician specialist response rates to web-based surveys. BMC Med Res Methodol. 2015;15:32. doi:10.1186/s12874-015-0016-z

25. Parashos P, Morgan MV, Messer HH. Response rate and non-response bias in a questionnaire survey of dentists. Community Dent Oral Epidemiol. 2005;33:9-16. doi:10.1111/j.1600-0528.2004.00181.x

26. Barclay S, Todd C, Finlay I, Grande G, Wyatt P. Not another questionnaire! Maximizing the response rate, pre-predicting non-response, and assessing non-response bias in postal questionnaire studies of GPs. Fam Pract. 2002;19:105-111. doi:10.1093/fampra/19.1.105

27. Nulty DD. The adequacy of response rates to online and paper surveys: what can be done? Assess Eval High Educ. 2008;33:301-314. doi:10.1080/02602930701293231

28. Baruch Y, Holtom HB. Survey response rate levels and trends in organizational research. Hum Relat. 2008;61:1139-1160. doi: $10.1177 / 0018726708094863$

29. Robertson DP, Keys W, Rautemaa-Richardson R, Burns R, Smith AJ. Management of severe acute dental infection. Br Med J. 2015;350: h1300. doi:10.1136/bmj.h1300

30. Fouad AF. Are antibiotics effective for endodontic pain? Endod Topics. 2002;3:52-66. doi:10.1034/j.1601-1546.2002.30106.x

31. Keiser K, Hargreaves KM. Building effective strategies for the management of endodontic pain. Endod Topics. 2002;3:93-105. doi:10.1034/j.1601-1546.2002.30109.x

32. Keenan JV, Farman AG, Fedorowicz Z, Newton JT. A Cochrane systematic review finds no evidence to support the use of antibiotics for pain relief in irreversible pulpitis. J Endod. 2006;32:87-92. doi:10.1016/j.joen.2005.10.029

33. Fedorowicz Z, van Zuuren EJ, Farman AG, Agnihotry A, AlLangawi JH. Antibiotic use for irreversible pulpitis. Cochrane Libr. 2013;12:CD004969.

34. Agnihotry A, Fedorowicz Z, van Zuuren EJ, Farman AG, AlLangawi JH. Antibiotic use for irreversible pulpitis. Cochrane Libr. 2019. doi:10.1002/14651858.CD004969.pub5

35. Virdee S, Seymour D, Bhakta S. Effective anesthesia of the acutely inflamed pulp: part 1. The acutely inflamed pulp. $\mathrm{Br}$ Dent $J$. 2015a;219:385-390. doi:10.1038/sj.bdj.2015.812

36. Virdee S, Bhakta S, Seymour D. Effective anesthesia of the acutely inflamed pulp: part 2. Clinical strategies. $\mathrm{Br}$ Dent $J$. 2015b;219:439-445. doi:10.1038/sj.bdj.2015.843

37. Bergenholtz G, Hörsted-Bindslev P, Reit C. Textbook of Endodontology. 2nd ed. Chichester: Wiley-Blackwell; 2010.

38. Kelley K, Clark B, Brown V, Sitzia J. Good practice in the conduct and reporting of survey research. Int $J$ Qual Health $C$. 2003;15:261-266. doi:10.1093/intqhe/mzg031

39. Fricker RD, Schonlau M. Advantages and disadvantages of Internet research surveys: evidence from the literature. Field Methods. 2002;14:347-367. doi:10.1177/152582202237725

40. Heiervang E, Goodman R. Advantages and limitations of web-based surveys: evidence from a child mental health survey. Soc Psychiatry Psychiatr Epidemiol. 2011;46:69-76. doi:10.1007/s00127-009-0171-9 


\section{Publish your work in this journal}

Infection and Drug Resistance is an international, peer-reviewed openaccess journal that focuses on the optimal treatment of infection (bacterial, fungal and viral) and the development and institution of preventive strategies to minimize the development and spread of resistance. The journal is specifically concerned with the epidemiology of

Submit your manuscript here: https://www.dovepress.com/infection-and-drug-resistance-journa| antibiotic resistance and the mechanisms of resistance development and diffusion in both hospitals and the community. The manuscript management system is completely online and includes a very quick and fair peerreview system, which is all easy to use. Visit http://www.dovepress.com/ testimonials.php to read real quotes from published authors. 